\title{
Inhibition of Nrf2/HO-1 signaling leads to increased activation of the NLRP3 inflammasome in osteoarthritis
}

Zhuming Chen ${ }^{1 \dagger}$, Huan Zhong ${ }^{1 \dagger}$, Jinsong Wei ${ }^{1 \dagger}$, Sien Lin ${ }^{1}$, Zhixian Zong ${ }^{1}$, Fan Gong ${ }^{1}$, Xinqia Huang ${ }^{1}$, Jinhui Sun ${ }^{2}$, Peng Li ${ }^{3}$, Hao Lin ${ }^{1}$, Bo Wei ${ }^{1}$ and Jiaqi Chu ${ }^{1,3^{*}}$ (D)

\begin{abstract}
Introduction: Osteoarthritis $(\mathrm{OA})$ is an inflammatory disease of the joints that causes progressive disability in the elderly. Reactive oxygen species (ROS) play an important role in OA development; they may activate the NLRP3 inflammasome, thereby inducing the secretion of proinflammatory IL-1 $\beta$ and IL-18, leading to the aggravation of the downstream inflammatory response. Nrf2 is a key transcription factor that regulates the expression of antioxidant enzymes that protect against oxidative stress and tissue damage. We aimed to explore the underlying mechanism of OA development by investigating NLRP3, ASC, Nrf2, and HO-1 expression in synovia and their regulatory networks in OA.
\end{abstract}

Methods: Human total knee replacement samples were subjected to histology and micro- $C T$ analysis to determine the pathological changes in the cartilage and subchondral bone and to assess the expression of inflammation-related markers in the synovial tissue by immunohistochemistry (IHC), qRT-PCR, and Western blot. To investigate these pathological changes in an OA animal model, adult Sprague-Dawley rats were subjected to anterior cruciate ligament transection and medial meniscectomy. Articular cartilage and subchondral bone changes and synovial tissue were also determined by the same methods used for the human samples. Finally, SW982 cells were stimulated with lipopolysaccharide (LPS) as an in vitro inflammatory cell model. The correlation between NLRP3 and Nrf2 expression was confirmed by knocking down NLRP3 or Nrf2.

Results: Cartilage destruction and subchondral bone sclerosis were found in the OA patients and OA model rats. Significantly increased expression levels of NLRP3, ASC, Nrf2, and HO-1 were found in the synovial tissue from OA patients. NLRP3, ASC, Nrf2, and HO-1 expression in the synovium was also upregulated in the OA group compared with the sham group. Furthermore, the NLRP3, Nrf2, HO-1, IL-1 3 , and IL-18 expression in LPS-treated SW982 cells was increased in a dose-dependent manner. As expected, the expression of NLRP3 was upregulated, and the expression of IL-1 $\beta$ and IL18 was downregulated after Nrf2 silencing. However, knocking down NLRP3 did not affect the expression of Nrf2.

Conclusions: ROS-induced oxidative stress may be the main cause of NLRP3 inflammasome activation and subsequent release of downstream factors during OA development. Nrf2/HO-1 signaling could be a key pathway for the activation of the NLRP3 inflammasome, which may contribute to the progression of OA. Herein, we discovered a novel role of Nrf2/ HO-1 signaling in the production of NLRP3, which may facilitate the prevention and treatment of OA.

Keywords: Osteoarthritis, Synovitis, NLRP3, ROS, Nrf2/HO-1 signaling

\footnotetext{
* Correspondence: chujiaqi@gdmu.edu.cn

'Zhuming Chen, Huan Zhong and Jinsong Wei contributed equally to this work.

'Orthopedic Center, Affiliated Hospital of Guangdong Medical University,

Zhanjiang 524001, China

${ }^{3}$ Stem Cell Research and Cellular Therapy Center, Affiliated Hospital of

Guangdong Medical University, Zhanjiang 524001, China

Full list of author information is available at the end of the article
}

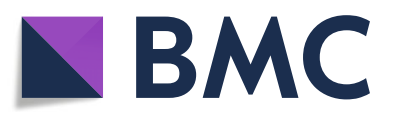

(c) The Author(s). 2019 Open Access This article is distributed under the terms of the Creative Commons Attribution 4.0 International License (http://creativecommons.org/licenses/by/4.0/), which permits unrestricted use, distribution, and reproduction in any medium, provided you give appropriate credit to the original author(s) and the source, provide a link to the Creative Commons license, and indicate if changes were made. The Creative Commons Public Domain Dedication waiver (http://creativecommons.org/publicdomain/zero/1.0/) applies to the data made available in this article, unless otherwise stated. 


\section{Background}

Osteoarthritis (OA), characterized by progressive cartilage degeneration and secondary synovial inflammation, is one of the most common chronic joint diseases affecting people of all ages, especially the elderly, and causes severe pain and physical disability [1]. Conservative nonsurgical management of OA involves physical interventions (e.g., weight reduction, moderate exercises, and stretching) and pharmacological therapies including nonsteroidal anti-inflammatory drugs, opioid analgesics, and intra-articular administration of steroids and hyaluronic acid, which is effective in alleviating pain but insufficient to reverse cartilage damage [2]. If patients suffer from severe joint damage or OA fails to respond to the conservative management, surgical treatments such as arthroplasty and osteotomy are generally recommended. However, the long-term outcome in surgery patients differs significantly [3]. Previously OA was considered a noninflammatory arthropathy, but today, it is generally accepted that it is an inflammatory disease, with synovitis present in most patients. Proinflammatory cytokines (e.g., interleukin-1 beta (IL-1 1 ), and IL-18), reactive oxygen species (ROS), inflammatory mediators, and biomechanical stress are regarded to be the major factors contributing to this scenario [4]. Furthermore, recent studies have demonstrated that dysregulated microRNAs, obesity-related metabolic factors, and inflammasome signaling molecules including Nod-like receptor protein 3 (NLRP3) are also involved in the progression of OA [5-8].

NLRP3, along with the adaptor protein apoptosisassociated speck-like protein containing a caspase recruitment domain (ASC), is one of the most studied inflammasome sensors, which activates caspase- 1 via the assembly of a complete inflammasome complex, subsequently leading to the secretion of pro-inflammatory cytokines IL-1 $\beta$, IL-18, and tumor necrosis factor alpha $[9,10]$. These play crucial roles in OA pathogenesis resulting in the release of cartilage-degrading enzymes, such as aggrecanases and metalloproteinases, from chondrocytes [11, 12]. Current ligands (known as NLRP3 agonists) that induce NLRP3 inflammasome formation include ATP, poreforming toxins, crystalline substances, nucleic acids, hyaluronan, and fungal, bacterial, and viral pathogens [13]. Likewise, recent studies suggest that intracellular ROS is elevated by various NLRP3 stimulators and enhanced ROS is essential for NLRP3 inflammasome activation [14]. The nuclear factor E2-related factor 2 (Nrf2) plays an important role in regulating the expression of antioxidant proteins, such as heme oxygenase 1 (HO-1), and is activated in response to ROS to protect cells against oxidative stress triggered by inflammation [15]. However, the relationship between NLRP3, ROS, and Nrf2 has not been determined.
In the present study, we addressed the question of whether the Nrf2 antioxidative pathway suppressed NLRP3-mediated proinflammatory responses in OA. To answer this question, we compared the expression changes of key molecules belonging to Nrf2 signaling and NLRP3 inflammasome pathway, using articular cartilage and synovial tissues obtained from both OA patients and a surgically induced rat model of OA. In addition, the relationship between NLRP3, ROS, and Nrf2 was explored in vitro through gene-specific inhibition of NLRP3 and Nrf2, respectively.

\section{Methods}

\section{Clinical specimen harvest}

We collected cartilage and synovium samples from OA patients during total knee arthroplasty surgery $(n=12 ; 4$ men and 8 women; age $66.4 \pm 7.2$ years, ranging from 56 to 78 years). The clinical samples for the control (CTL) group were collected from patients with no previous history of OA whose knees were amputated due to trauma ( $n=5 ; 1$ man and 4 women, aged $50.0 \pm 23.4$ years, ranging from 15 to 79 years). All patients satisfied the American College of Rheumatology clinical criteria for primary knee OA [16]. Samples of synovium and cartilage were collected within half an hour of the surgery, stored into phosphate-buffered saline, and transported to the laboratory within $15 \mathrm{~min}$. Half of each specimen was fixed in formalin for later paraffin embedding, and the other half of each sample was frozen immediately in liquid nitrogen for use in IHC and Western blot analyses and RNA extraction. All clinical procedures were approved by the Committee of Medical Ethics at the Affiliated Hospital of Guangdong Medical University (PJ2017072; Sept 7, 2017). The clinical specimens (cartilage and synovium) were obtained from donors after they signed an informed consent form.

\section{Rat models of osteoarthritis and tissue harvest}

Four-month-old Sprague-Dawley (SD) rats were purchased from the Guangdong Medical Laboratory Animal Center of China. Rats were housed with free access to pelleted commercial food and water and were individually housed with a 12-h dark/light cycle under controlled conditions $\left(25^{\circ} \mathrm{C}, 70 \%\right.$ humidity). Animals were randomly allocated to the sham group $(n=8)$ or OA group $(n=16)$. For the OA model, the right knee joints of the rats were subjected to both anterior cruciate ligament transection and medial meniscus destabilization (ACLT + MMD). The sham group received only a skin and capsule incision, and samples were collected at 4 and 8 weeks after the sham operation. OA group samples were collected at $4(n=8)$ or $8(n=8)$ weeks after operations. All protocols involving animals were approved by the Animal Care and Experiment Committee of Guangdong Medical 
University and followed the National Institutes of Health guidelines for the Care and Use of Laboratory Animals.

\section{Cell culture}

The SW982 cell line was purchased from the American Type Culture Collection (ATCC, Manassas, VA, USA), and the cells were cultured in Dulbecco's modified Eagle's medium (DMEM) containing 10\% fetal bovine serum (FBS) and an antibiotic-antimycotic solution (all from Gibco, Grand Island, NY, USA), at $37^{\circ} \mathrm{C}$ in humidified conditions with $5 \% \mathrm{CO}_{2}$. The medium was changed every 3 days. Cells were treated with 0, 50, 100, and $200 \mathrm{ng} / \mathrm{ml}$ LPS (Sigma, St. Louis, MO, USA) in a 10$\mathrm{cm}$ Petri dish for $24 \mathrm{~h}$.

\section{siRNA transfection}

SW982 cells were transfected in 6-well plates with Nrf2specific siRNA using Lipofectamine ${ }^{\circ}$ LTX \& PLUS $^{\text {ma }}$ Reagent (Life Technologies, Carlsbad, CA, USA) in accordance with the manufacturer's instructions. The expression of Nrf2 and downstream proteins was examined $48 \mathrm{~h}$ after transfection by using qRT-PCR and Western blotting.

\section{shRNA lentiviral particle transduction}

The control and NLRP3 shRNA lentiviral particles were purchased from Santa Cruz Biotechnology (CA, USA). SW982 cells were seeded in a 24-well plate, and cells were infected with lentiviral particles for $72 \mathrm{~h}$. Then, $4 \mu \mathrm{g} / \mathrm{ml}$ puromycin (Santa Cruz Biotechnology) was added to the medium to select cells successfully infected with the virus.

\section{Intracellular ROS detection by DHE}

ROS production in SW982 cells was measured by using dihydroethidium (DHE, Santa Cruz) fluorescent dye. Cells on glass coverslips were incubated in Hank's balanced salt solution (HBSS, Gibco) containing $\mathrm{CaCl}_{2}$ and $\mathrm{MgCl}_{2}$ with $10 \mu \mathrm{mol} / \mathrm{L}$ DHE in a light-protected chamber at $37^{\circ} \mathrm{C}$ for $30 \mathrm{~min}$. Then, the cells were washed with HBSS and loaded onto microscope slides using a mounting medium containing DAPI (Vector Laboratories, CA, USA), and fluorescence microscopy was used to capture images of the cells. In addition, ROS levels were determined by flow cytometry at an excitation wavelength of $535 \mathrm{~nm}$ and an emission wavelength of $610 \mathrm{~nm}$. All experiments were performed in triplicate.

\section{Micro-computed tomography (CT) analysis}

Articular cartilage tissues were fixed overnight in $10 \%$ formalin. The microstructure of the samples was analyzed using micro-CT (SkyScan1172; Bruker, Kontich, Belgium). For the clinical samples, the three-dimensional (3D) images showing the whole subchondral bone were used for analysis; for the animal study, 50 sagittal images of the tibia subchondral bone were evaluated at a global threshold $\left(158 \mathrm{mg}\right.$ hydroxyapatite $\left./ \mathrm{cm}^{3}\right)$ to reconstruct a $3 \mathrm{D}$ model, and a Gaussian filter ( sigma $=0.8$, support $=$ 2 ) was used to suppress noise. The bone mineral density (BMD) and bone volume/total tissue volume (BV/TV) were analyzed as 3D structural parameters with a builtin program. All of the micro-CT analyses were performed using the Scanco micro-CT software analysis system (Scanco Medical, v. 2013).

\section{Histological and immunochemical analysis}

Articular cartilage was decalcified using 10\% ethylenediaminetetraacetic acid (EDTA, Solarbio, Beijing, China) for 2 weeks and embedded in paraffin blocks. The blocks were cut to a thickness of $5 \mu \mathrm{m}$ at distinct planes using a microtome (Leica Microsystems, Germany). Then, the sections were subjected to safranin $\mathrm{O} /$ fast green, Masson, hematoxylin and eosin (H\&E), and immunohistochemical staining (all from Solarbio).

For immunohistochemical staining, horseradish peroxidase-streptavidin in the detection system (\#CW0128, CWBIO, China) was utilized and diluted according to the appropriate ratio with the following antibodies: NLRP3 (1: 100, \#13158, Cell Signaling Technology, Danvers, MA, USA), ASC (1:100, \#78977, Cell Signaling Technology, Danvers, MA, USA), Nrf2 (1:100, \#ab62352, Abcam, USA), and HO-1 (1:100, \#ADI-SPA-895, ENZO, USA). Subsequently, counterstaining was performed with hematoxylin. Photographs of the selected areas were taken using an optical microscope and quantified with Image-Pro Plus 6.0 software (Media Cybernetics, Silver Spring, MD, USA) based on the histological staining. The optical density of the positively stained cells was measured; the measurement was repeated three times in randomly selected sections of the region of interest for each sample.

For cartilage analysis and scoring, proteoglycan in the articular cartilage was measured by safranin $\mathrm{O} /$ green staining and blindly scored by three independent researchers based on the OARSI histologic scoring system [17]. Briefly, the depth of the cartilage damage and the extent of the surface damage was scored in a blinded manner at four different locations in the rat knee joint, i.e., the lateral and medial tibia and femur. The OA score was defined as the product of the multiplication of these two scores. The mean OA score was calculated using the scores for the four individual locations examined by three researchers.

\section{Gene expression analysis}

For the gene expression analysis, the samples were collected, and total RNA was extracted using TRIzol reagent (Invitrogen Life Technologies, Carlsbad, CA, USA) according to the manufacturer's instructions. Total RNA $(1 \mu \mathrm{g})$ was reverse transcribed to cDNA using Prime 
Script RT Enzyme mix at $37^{\circ} \mathrm{C}$ for $15 \mathrm{~min}$, followed by incubation at $85^{\circ} \mathrm{C}$ for $5 \mathrm{~s}$. The primer sequences are shown in Table 1. GAPDH was used as an internal control. All procedures were performed with an ABI 7500 Fast Real-Time PCR system (Applied Biosystems, Carlsbad, CA, USA) under the following cycling conditions: $95^{\circ} \mathrm{C}$ for $30 \mathrm{~s}$, followed by 40 cycles at $95^{\circ} \mathrm{C}$ for $5 \mathrm{~s}$ and $60^{\circ} \mathrm{C}$ for $34 \mathrm{~s}$. The relative quantification of the gene expression was calculated with the $2^{-\Delta \Delta C T}$ values normalized to the GAPDH values. Primer sequences were determined through GenBank, as shown in Table 1, and were synthesized by Biotechnology Co. Ltd. (Shanghai).

\section{Protein analysis}

The protein used for Western blotting was extracted using RIPA buffer (\#89900, Thermo Fisher Scientific, Grand Island, NY, USA). Then, the lysates were centrifuged at $1000 \times g$ for $5 \mathrm{~min}$ to remove tissue. Protein concentrations were determined using a BCA protein assay kit (\#P0010, Beyotime Biotechnology, China). Total protein $(20 \mu \mathrm{g})$ was separated by $10 \%$ or $12 \%$ SDS-polyacrylamide gel electrophoresis (SDS-PAGE) and transferred to polyvinylidene fluoride (PVDF) membranes (\#R7EA2546B, Millipore Corp, GER). The membranes were then blocked in TBS-T containing 5\% skim milk for $1 \mathrm{~h}$ and incubated with primary antibodies against NLRP3 (1:1000, \#13158, Cell Signaling Technology), Nrf2 (1:1000, \#ab62352, Abcam), P-Nrf2(1:1000, \#ab76026, Abcam), HO-1 (1:500, \#ADI-SPA-895, ENZO), IL-1ß (1:1000, \#12703S, Sigma), IL-18 (1:1000, \#sab2701968, Sigma), $\alpha$-tubulin (1:1000, \#sc-32293, Santa Cruz), and GAPDH (1:1000, \#sc-25778, Santa Cruz) overnight at $4{ }^{\circ} \mathrm{C}$. The membranes were then washed with TBS-T and incubated with the secondary antibody at the recommended dilution in blocking buffer at room temperature for $2 \mathrm{~h}$. The blots were then rinsed 3 times for $5 \mathrm{~min}$ with TBS-T, and images were captured using a CCD camera (Azure Biosystems C500, USA).

\section{Enzyme-linked immunosorbent assay (ELISA)}

For clinical samples, IL-1 $\beta$ levels in the serum were detected using an IL-1 $\beta$ ELISA kit according to the protocol provided by the manufacturer (\#MM-0181H1, MEIMIAN, China). The results were obtained based on the linear range of the standard curve. All of the samples were assessed in triplicate.

\section{Statistical analysis}

All data are presented as mean \pm standard deviation (SD). Statistical analysis was performed with the paired Student $t$ test to compare mean values between 2 groups. One-way analysis of variance (ANOVA) with Turkey Kramer multiple comparisons test was used to compare mean values using the SPSS software (version 19.0 , SPSS Inc., USA). $P<0.05$ was considered statistically significant.

\section{Results \\ Cartilage destruction and subchondral bone sclerosis in OA patients}

For the clinical samples, safranin $\mathrm{O} /$ fast green and $\mathrm{H} \& \mathrm{E}$ staining were used. The results showed that the surface of the cartilage was relatively intact with the appropriate amount of chondrocytes in the control group. However, there was a significant reduction in cartilage thickness and chondrocyte numbers in the OA group cartilage (Fig. 1a, b). In addition, based on the OARSI histologic grading system, compared with that in the control group $(2.50 \pm 0.28, n=4)$, the cartilage damage in the OA group $(5.75 \pm 0.47, n=4)$ was more severe (Fig. 1e). Furthermore, 2D images and 3D reconstructed images captured from the micro-CT analysis showed that the BMD of OA patients was significantly higher than that of the healthy controls $(0.21 \pm 0.01$ vs $0.39 \pm 0.05 \mathrm{BV} / \mathrm{TV}$ and $144.70 \pm 19.81 \mathrm{mg} / \mathrm{cm}^{3}$ vs $327.50 \pm 38.33 \mathrm{mg} / \mathrm{cm}^{3}$ BMD, $P<0.05, n=4$; Fig. 1c, d, f, g).

Table 1 Primer sequences for real-time PCR

\begin{tabular}{|c|c|c|c|c|}
\hline \multirow{2}{*}{$\begin{array}{l}\text { Gene name } \\
\text { Nrf2 }\end{array}$} & \multicolumn{2}{|c|}{ Primer sequence ( $5^{\prime}$ to $3^{\prime}$ ) } & \multirow{2}{*}{$\begin{array}{l}\text { Product (bp) } \\
119\end{array}$} & \multirow{2}{*}{$\begin{array}{l}\text { GenBank serial number } \\
\text { NM_001313901.1 }\end{array}$} \\
\hline & Forward & GGTTGCCCACATTCCCAAATC & & \\
\hline & Reverse & CAAGTGACTGAAACGTAGCCG & & \\
\hline \multirow[t]{2}{*}{ NLRP3 } & Forward & AAAGGAAGTGGACTGCGAGA & 129 & XM_011544055.2 \\
\hline & Reverse & TTCAAACGACTCCCTGGAAC & & \\
\hline \multirow[t]{2}{*}{$\mathrm{HO}-1$} & Forward & TTCAAGCAGCTCTACCGCTC & 90 & NM_002133.2 \\
\hline & Reverse & GAACGCAGTCTTGGCCTCTT & & \\
\hline \multirow[t]{2}{*}{$\mid L-1 \beta$} & Forward & CCACAGACCTTCCAGGAGAA & 121 & XM_017003988.1 \\
\hline & Reverse & GTGATCGTACAGGTGCATCG & & \\
\hline \multirow[t]{2}{*}{ |L-18 } & Forward & TGCATCAACTTTGTGGCAAT & 169 & XM_011542806.2 \\
\hline & Reverse & ATAGAGGCCGATTTCCTTGG & & \\
\hline \multirow[t]{2}{*}{ GAPDH } & Forward & GGACTCATGACCACAGTCCAT & 109 & NM_000194.2 \\
\hline & Reverse & CAGGGATGATGTTCTGGAGAG & & \\
\hline
\end{tabular}




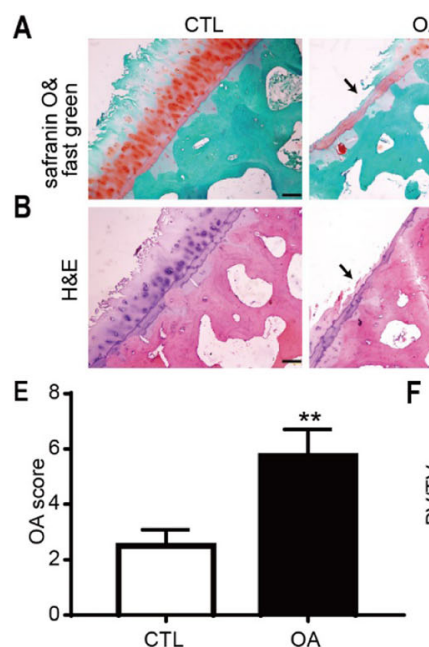

$O A$

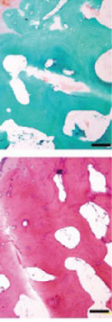

$\mathbf{F}$

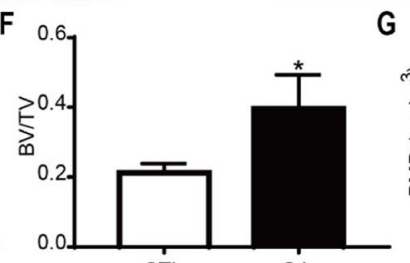

CTL

G

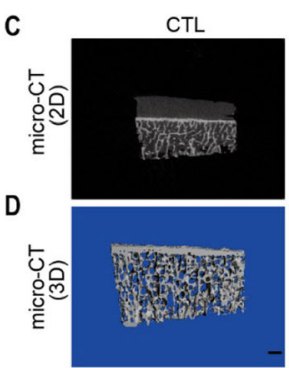

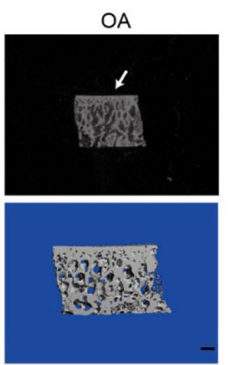

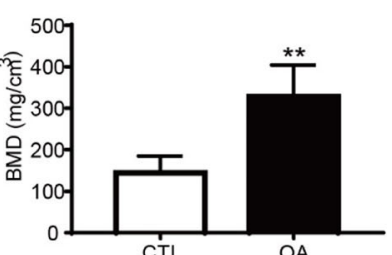

Fig. 1 Histological and microstructural changes in the subchondral bone of the superior articular surface on the tibia. Representative images are shown from repeated experiments. a, b Safranin O/fast green- and H\&E-stained sections showing the damaged region of the articular surface (indicated by black arrows; scale bar $=100 \mu \mathrm{m}$ ). $\mathbf{c}, \mathbf{d} 2 \mathrm{D}$ and 3D images of the subchondral bone of the tibia showing the damaged region of the articular surface (indicated by white arrows; scale bar $=1 \mathrm{~mm}$ ). e Semiquantitative results of the OARSI scoring system. $\mathbf{f}, \mathbf{g}$ Bone quantification results of the subchondral bone of the tibia from healthy controls and OA patients, including the BV/TV (trabecular BV per TV) and BMD. ( $n=4$, ${ }^{*} P<0.05,{ }^{* *} P<0.01$ vs $(T L)$

\section{Expression of inflammasome proteins and Nrf2/HO-1 in} the OA cartilage synovium

Nrf2, HO-1, NLRP3, and ASC expression levels in the synovium and the phenotype of synovium were investigated in OA patients by immunohistochemistry. Colored staining, representing the expression of Nrf2, HO-1, NLRP3, or ASC, was observed in the synovial membranes of the OA patients (Fig. 2a). Compared with that in the control group, the expression of NLRP3 and ASC in the OA group was significantly increased $(0.12 \pm 0.01, n=12$ vs $0.05 \pm 0.01, n=5, P<0.01 ; 0.13 \pm 0.01, n=12$ vs $0.06 \pm$ $0.01, n=5, P<0.01$; Fig. $2 \mathrm{~b}, \mathrm{c})$. Moreover, the results also indicated that the expression of $\mathrm{Nrf} 2$ and $\mathrm{HO}-1$ was increased in the OA group compared with the control group $(0.15 \pm 0.02, n=12$ vs $0.05 \pm 0.01, n=5, P<0.01$, and $0.14 \pm 0.02, n=12$ vs $0.07 \pm 0.01, n=5, P<0.05$; Fig. 2 d, e).

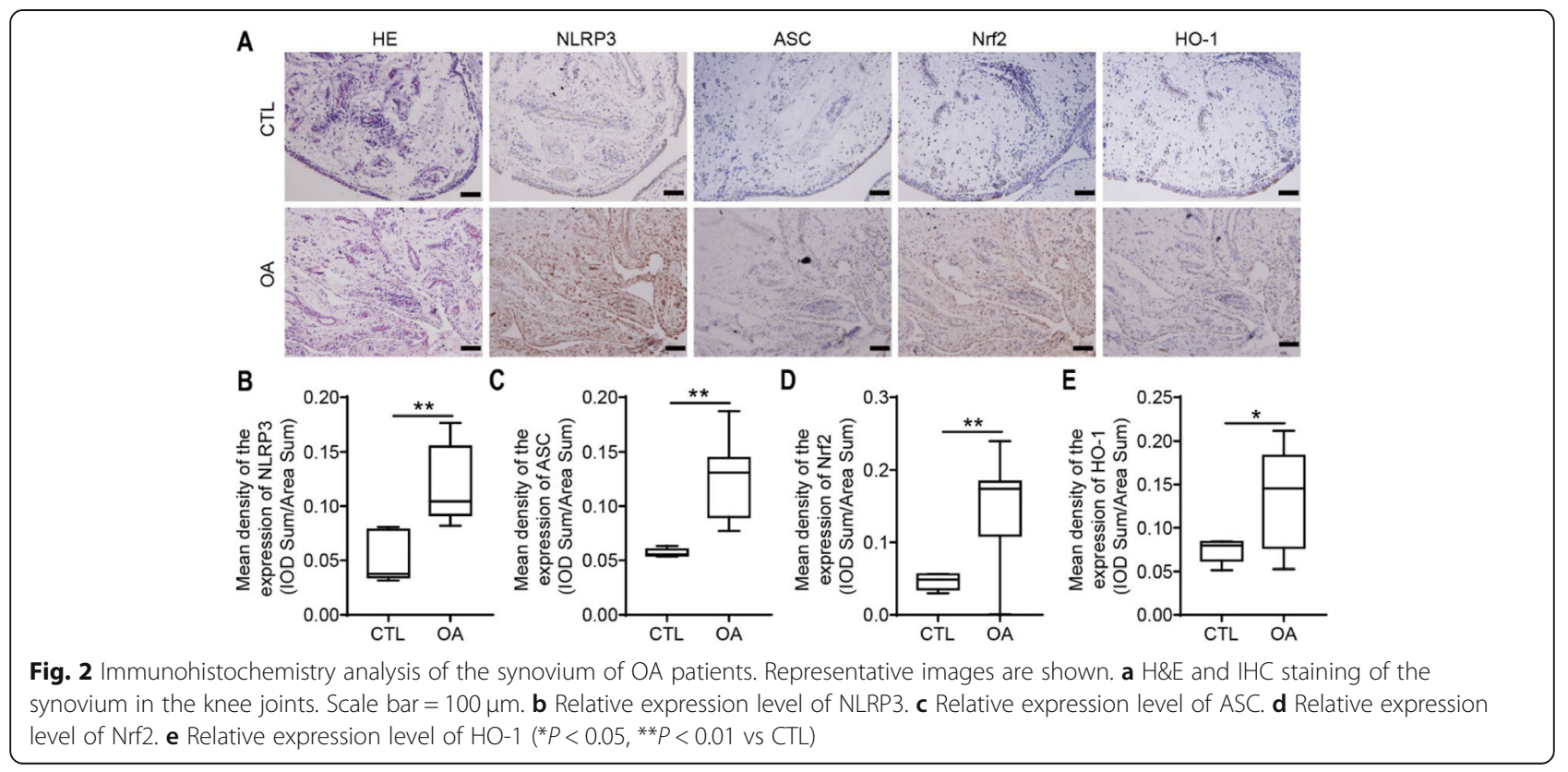



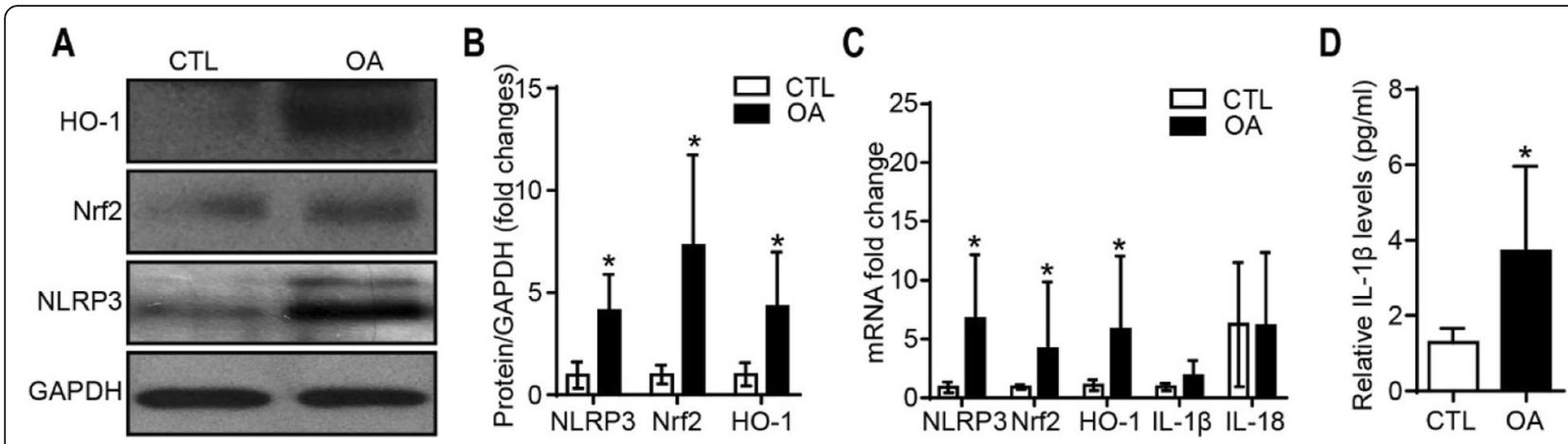

Fig. 3 Relative protein and mRNA expression levels in the synovium and relative IL-1 $\beta$ level in the serum of OA patients. Representative images are shown from experiments. a, b Nrf2, NLRP3, and HO-1 expression levels were determined using Western blot analysis. c Nrf2, NLRP3, and HO-1 mRNA expression levels were examined using qRT-PCR. $\mathbf{d}$ Expression level of IL-1 $\beta$ in the serum, assessed by ELISA. (n.S.P $P>0.05,{ }^{*} P<0.05,{ }^{* *} P<0.01$ vs $\left.C T L\right)$

Synovial NLRP3, Nrf2, and HO-1 expression, and serum inflammatory factor IL-1 $\beta$ levels in OA patients

For clinical samples, Western blot analyses were employed to compare the expression levels of $\mathrm{Nrf2}$, NLRP3, and HO-1 in OA patients with those in the healthy controls. Nrf2, NLRP3, and HO-1 expression was upregulated dramatically in OA patients (Fig. 3a, b). In addition, as shown in Fig. 3c, the mRNA fold changes of Nrf2, NLRP3, and HO-1 were also increased in the synovium as assessed by qRT-PCR, but there were no significant differences in IL-1 $\beta$ or IL-18 expression.
However, the ELISA results showed that the level of IL$1 \beta$ was significantly elevated in the serum of OA patients compared with the healthy controls $(3.71 \pm 0.92 \mathrm{pg} / \mathrm{ml}$ vs $1.28 \pm 0.15 \mathrm{pg} / \mathrm{ml}, n=6, P<0.05$; Fig. 3d).

\section{Cartilage and subchondral bone structure of $O A$ animal models}

Safranin O/fast green staining showed that the structure of the cartilage remained relatively intact in the shamoperated group, whereas the surface of the OA-group cartilage 4 and 8 weeks after operation was uneven with

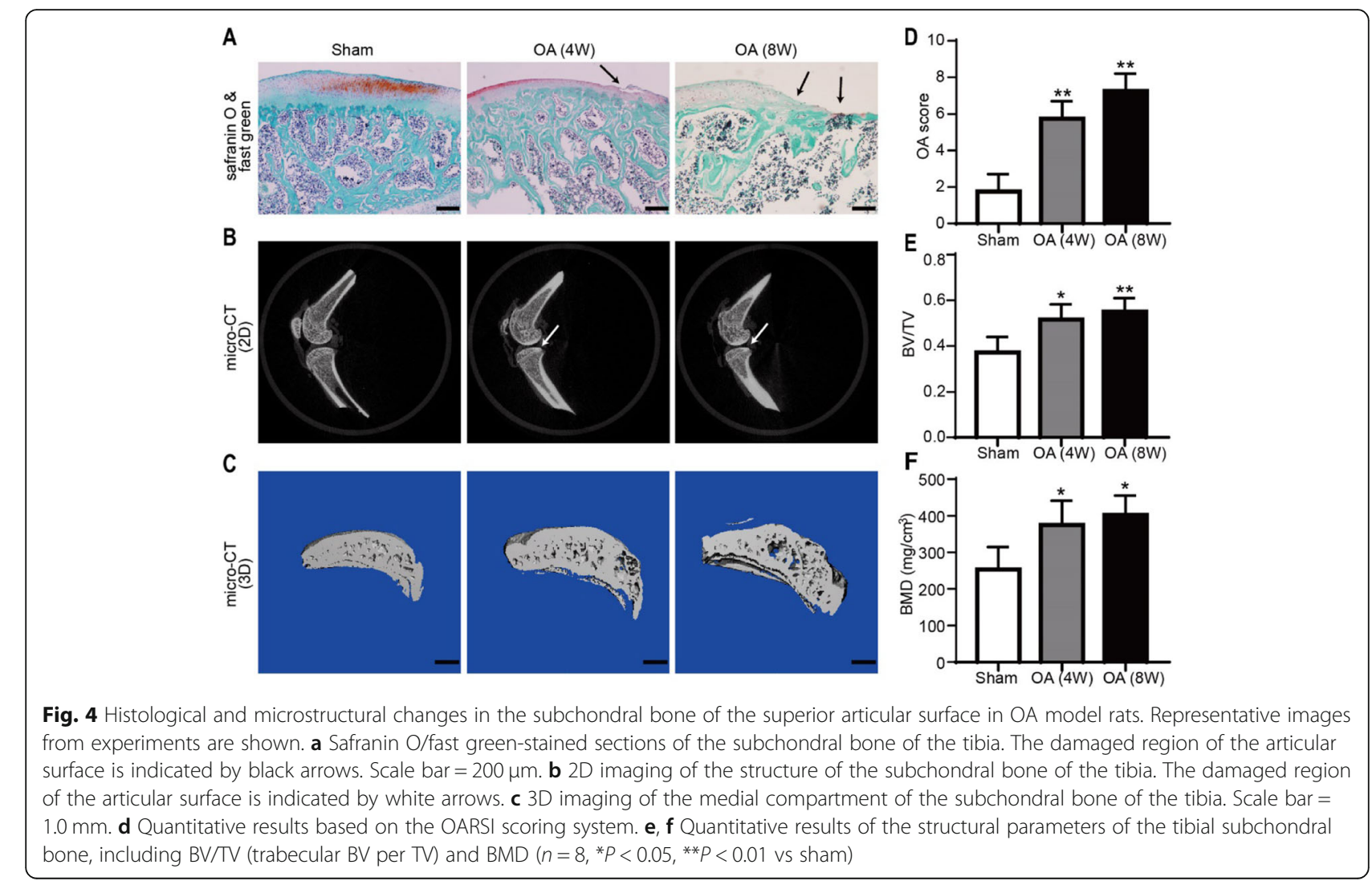


the disappearance of tide marks (Fig. 4a). The results based on the OARSI scoring system indicated that the cartilage destruction of the OA 4-week $(5.75 \pm 0.83, n=$ $4)$ and 8-week $(7.25 \pm 0.82, n=4)$ groups was severe compared with that of the sham group $(0.75 \pm 0.43, n=$ 4; Fig. 4d). The 2D images and reconstructed 3D images obtained from the micro-CT were used to assess the microarchitecture of the rat subchondral bone in all groups and showed that the subchondral bone was hardened in the OA group compared with the sham group (Fig. 4b, c). The respective values were $0.51 \pm 0.06$ and $0.55 \pm 0.05$ vs $0.37 \pm 0.06$ for the BV/TV and $375.40 \pm$ $57.95 \mathrm{mg} / \mathrm{cm}^{3}$ and $402.95 \pm 46.08 \mathrm{mg} / \mathrm{cm}^{3}$ vs $253.45 \pm$ $53.11 \mathrm{mg} / \mathrm{cm}^{3}$ for the BMD $(P<0.05, n=3$; Fig. $4 \mathrm{e}, \mathrm{f})$.

\section{Inflammation of the synovium in an $\mathrm{OA}$ animal model}

The synovia of the knee joints from the OA model rats were harvested for Masson and H\&E staining 4 or 8 weeks after the operation. Compared with the sham group, the 4-week and 8-week OA groups displayed pathological changes in the synovium and cell infiltration. The lesions of the 8-week OA group were the most severe. IHC staining showed that the expression of NLRP3, ASC, Nrf2, and HO-1 in the synovial tissue of the OA group was significantly higher than that of the sham group. Nrf2, HO-1, NLRP3, and ASC expression in the synovium and the phenotype of the synovium were investigated in OA model rats by histochemistry. Colored staining, representing the expression of Nrf2, HO-1, NLRP3, and ASC, was observed in the synovium of OA rats (Fig. 5a). Compared with that in the sham group, the expression of NLRP3, ASC, Nrf2, and HO-1 in the 4-week OA group was increased (Fig. 5b-e). Notably, the expression of Nrf2 and $\mathrm{HO}-1$ in the OA 8-week group was increased significantly compared with that in the sham group (Fig. 5d, e).

\section{Expression of ROS in SW982 cells treated with LPS}

LPS treatment increased the inducible ROS production in SW982 cells. The results are shown in Fig. 6. ROS levels were assessed by DHE staining, and LPS treatment promoted the expression of ROS in a dosedependent manner. Furthermore, a flow cytometric analysis was also performed for further confirmation of this finding.

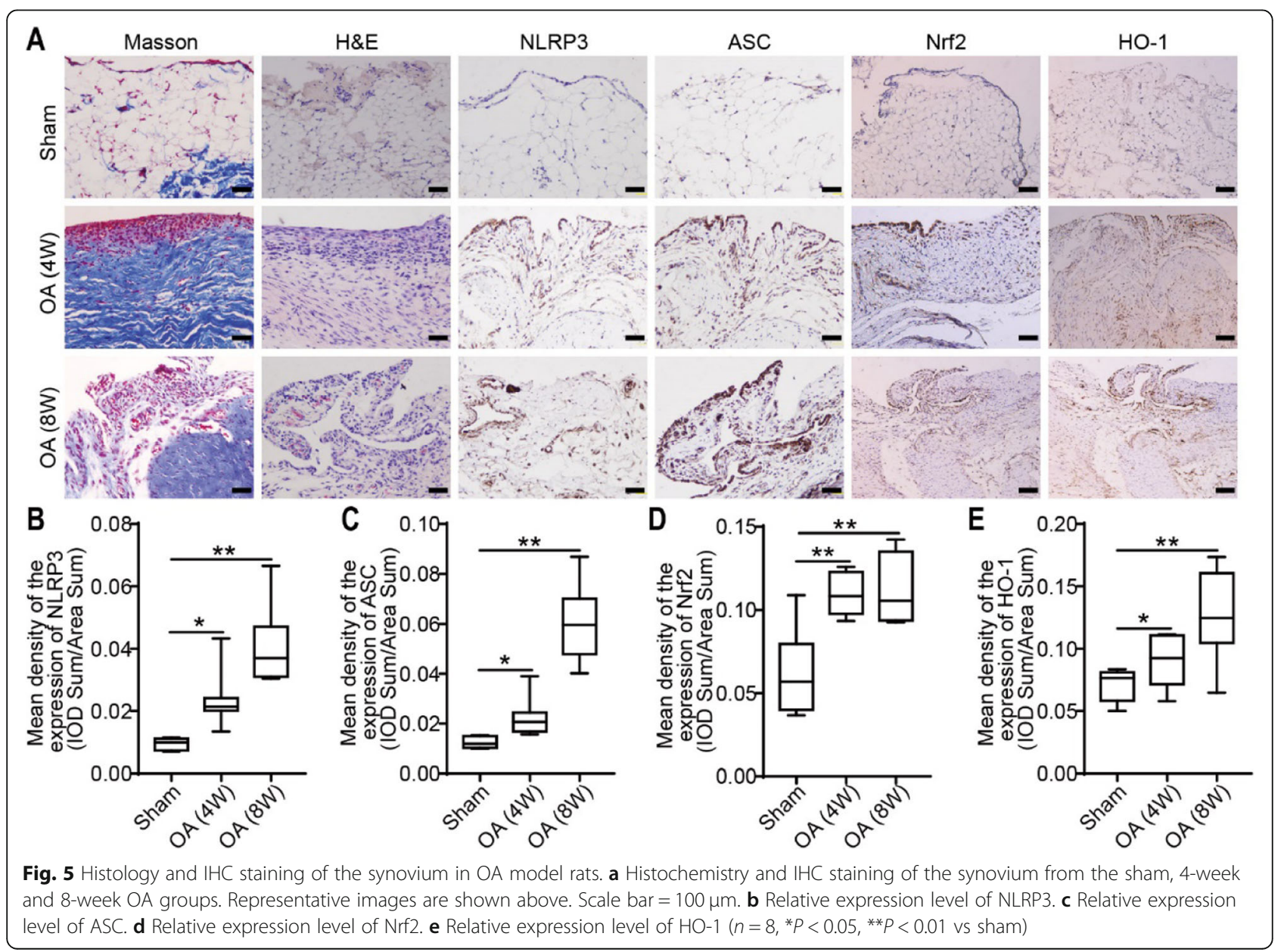



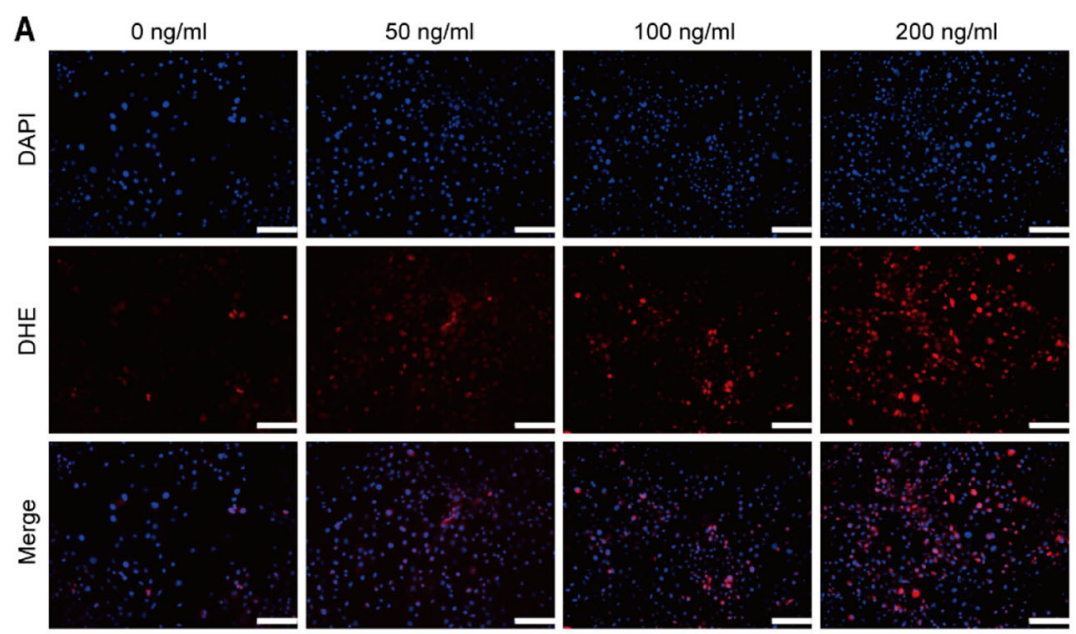

B
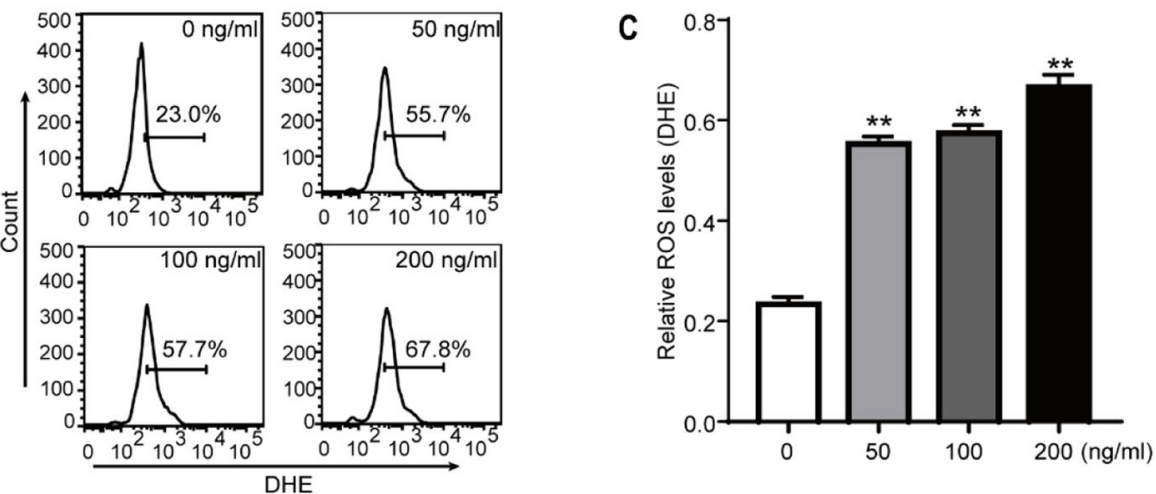

Fig. 6 LPS treatment increases ROS generation in SW982 cells. a DHE staining (red fluorescence) was performed to evaluate the ROS levels. Representative images are shown from repeated experiments. Scale bar $=100 \mu \mathrm{m}$. b Flow cytometric analysis of the generation of ROS in cells treated with different concentrations of LPS for $24 \mathrm{~h}$. c Relative levels of ROS ( $n=3,{ }^{* *} P<0.01 \mathrm{vs} \mathrm{CTL)}$
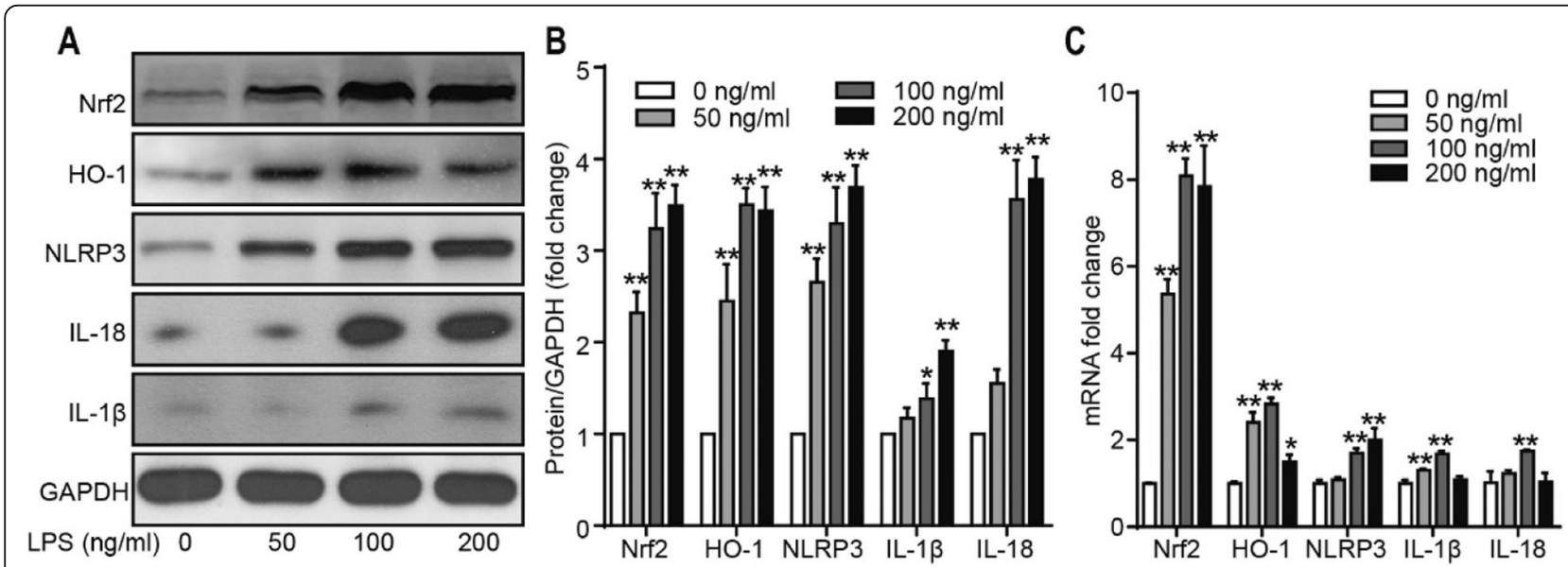

Fig. 7 ROS-associated inflammation is induced in SW982 cells by treatment with LPS for $24 \mathrm{~h}$. $\mathbf{a}$, b Representative images of Western blots depicting the levels of NLRP3, Nrf2, IL-1 $\beta$, and IL-18 in SW982 cells and the protein/GAPDH ratios as determined by the densitometric analysis of Western blots. c NLRP3, IL-1 $\beta, I L-18$, Nrf2, and HO-1 mRNA expression examined using qRT-PCR $(n=3, * P<0.05$, ${ }^{* *} P<0.01$ vs $(T L)$ 


\section{LPS-induced inflammation associated with ROS}

NLRP3 is a protein complex that is associated with ROS-induced inflammation. To understand the activation mechanism of the NLRP3 inflammasome, we studied the expression of related proteins and mRNAs in SW982 cells after stimulation with different concentrations of LPS. As shown in Fig. 7, the Western blot and qRT-PCR results indicated that the expression of Nrf2, HO-1, NLRP3, IL-1 $\beta$, and IL-18 was upregulated by LPS treatment in a dose-dependent manner.

\section{Inflammation response to NLRP3 knockdown in SW982 cells}

To evaluate the roles of the NLRP3 inflammasome, cells were infected with lentiviral particles containing shRNA specific to NLRP3 and then stimulated with LPS for 24 h. The Western blot and qRT-PCR results showed that the expression of IL-1 $\beta$ and IL-18 was downregulated significantly. As shown in Fig. 8, NLRP3 shRNA significantly reduced the protein and mRNA levels of NLRP3, IL-1 $\beta$, and IL-18. However, the protein and mRNA levels of Nrf2 and HO-1 did not change dramatically with or without LPS stimulation. These results suggest that the NLRP3 inflammasome is vital for LPS-induced IL-1 $\beta$ and IL-18 expression in SW982 cells. In addition, each component of the NLRP3 inflammasome is involved in IL-1 $\beta$ and IL-18 production.

\section{Inhibition of the Nrf2 pathway alleviates the inflammation induced by NLRP3 in response to LPS treatment}

To identify the relationship between the NLRP3 inflammasome and Nrf2, we transfected SW982 cells with siRNA specific for Nrf2 and stimulated them with LPS for $24 \mathrm{~h}$. As shown in Fig. 9a, no significant difference was observed in the ROS level between cells treated with control siRNA and
siNrf2, as assessed by DHE staining. However, the LPSinduced ROS production was enhanced after silencing of Nrf2. Furthermore, the downregulation of Nrf2 expression increased the expression of NLRP3 (Fig. 9b-d), which means that LPS-induced NLRP3 inflammasome activation may be enhanced after Nrf2 silencing.

\section{Discussion}

Articular cartilage, the subchondral bone and the synovium are pivotal in maintaining the stability of the joint. Degeneration of the cartilage and subchondral bone plays a key role in the progression of OA. The synovium, which functions as a part of the lubrication, nutrition, and circulation system of the synovial fluid of the joint, plays an important role in maintaining the homeostasis of the joint. Furthermore, it contributes to the degeneration of the joint in OA by releasing inflammatory molecules $[4,18]$. Evidence suggests that the NLRP3 inflammasome is involved in the development of OA, leading to the degradation of cartilage and synovial inflammation $[8,18]$. In this study, we found that NLRP3 and ASC were highly expressed in the synovia of OA patients, as well as in the OA model rats, which is consistent with previous studies [19-21]. Moreover, several studies have confirmed that inflammasomes promote the expression and maturation of proinflammatory cytokines, including IL-1 $\beta$ and IL-18 [22, 23]. As welldocumented inflammatory cytokines, IL-1 $\beta$ and IL-18 have been shown to be involved in the occurrence and development of various diseases, including OA $[24,25]$. A previous study investigating the secretion of IL- $1 \beta$ and IL-18 by knee joint articular cartilage and synovium explants from OA patients demonstrated that the release of those two cytokines from synovium was remarkably greater than that from articular cartilage [26], implying under pathological conditions, IL-1 $\beta$ and IL-18 may be

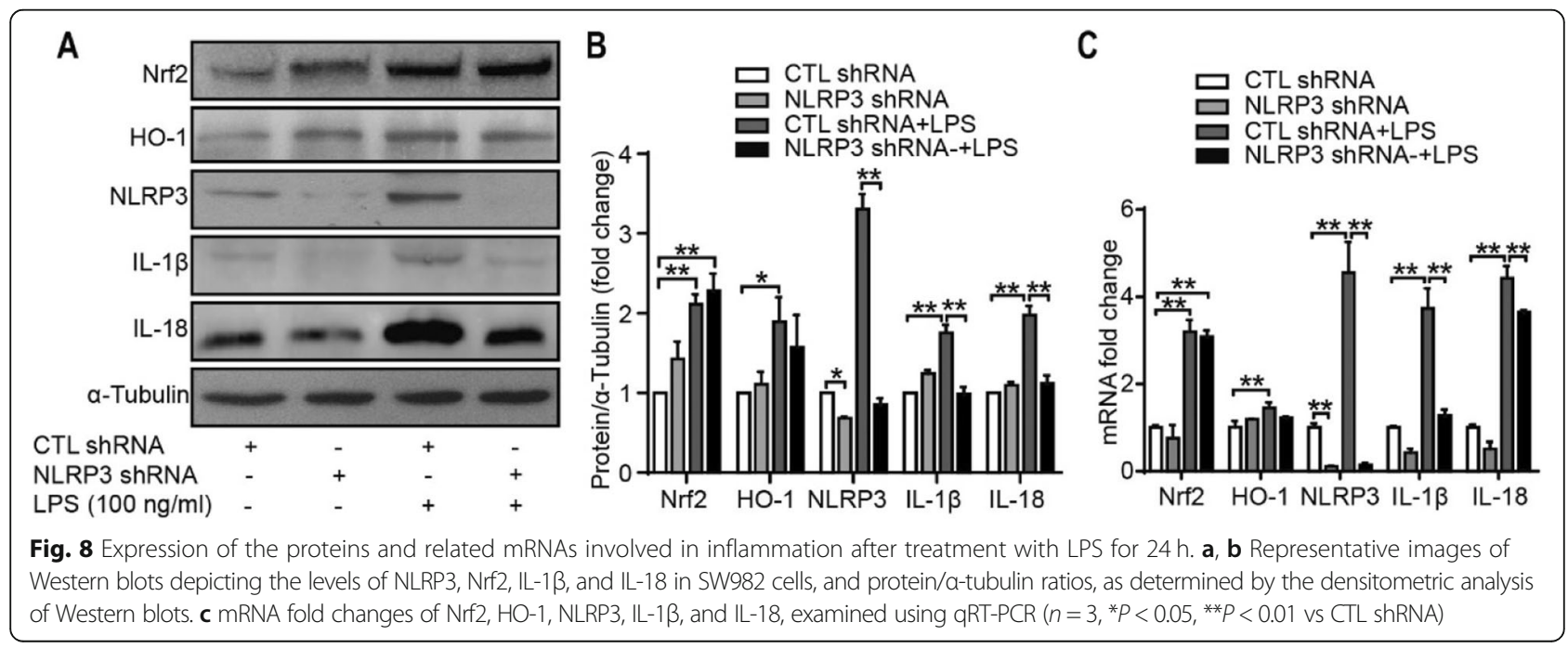




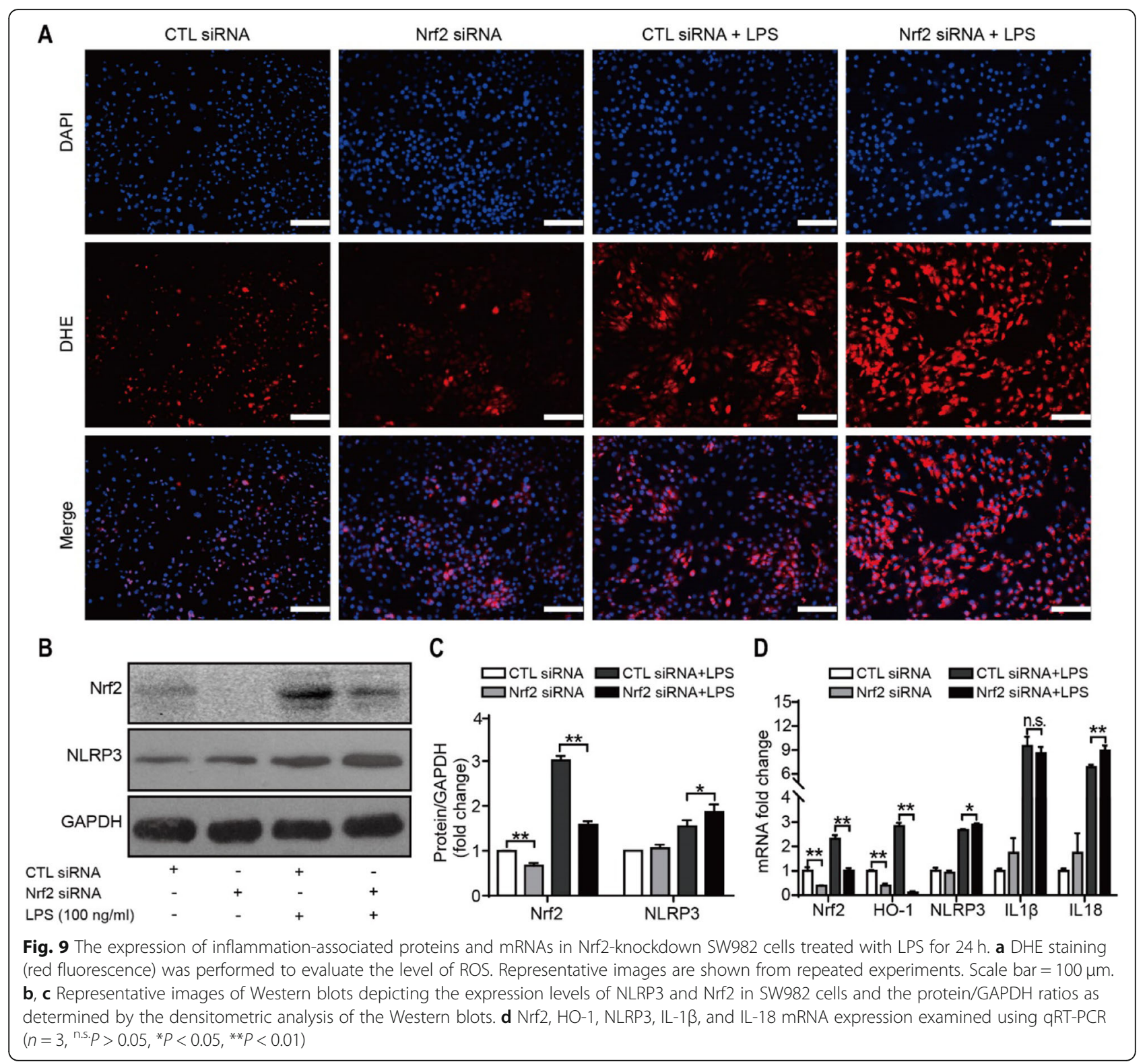

mainly from immune cells in synovium, rather than chondrocytes in cartilage. Meanwhile, results obtained from a study of hand osteoarthritis (HOA) showed NLRP3 protein expression in the peripheral blood mononuclear cells derived from nonerosive HOA patients was much higher compared to that from erosive HOA patients and healthy subjects [27]. Although the exact reason for this is still unknown, this finding is well in line with our current result showing enhanced NLRP3 expression in knee OA. It should be noted, however, that the role of NLRP3 in OA pathogenesis seems highly controversial. Indeed, while some studies suggested a contributing impact of NLRP3 on OA [28-30], others indicated that NLRP3 was not essential for cartilage degradation in OA $[26,31]$. These conflicting results regarding NLRP3 may result from species difference in experimental OA models and variability in the method of $\mathrm{OA}$ induction.

ROS exist as both injurious and salutary species and play important roles in various physiological processes at low concentrations; however, the overproduction of ROS in cells leads to the onset and progression of OA [32]. It has been reported that ROS play an essential role in proinflammatory responses, affecting the activity of antioxidant enzymes and oxidative stress, leading to the activation of the NLRP3 inflammasome [28, 33, 34]. Accordingly, our study provides novel evidence suggesting that the expression level of Nrf2 and its downstream factor $\mathrm{HO}-1$ is 
upregulated in the synovia of OA patients, which indicates that Nrf2, HO-1, and the NLRP3 inflammasome may play a crucial role in the progression of $\mathrm{OA}$.

$\mathrm{Nrf2}$ is an oxidative stress sensor and key transcription factor that protects cells from foreign substances and oxidative damage. Previous studies have shown that under physiological circumstances, Nrf2 is mainly present in the cytoplasm; however, when the level of ROS is elevated, the transcription of antioxidative stress proteins, including $\mathrm{HO}-1$, is enhanced by $\mathrm{Nrf} 2[35,36]$. In addition, evidence suggests that the oxidative stress response transcription factor Nrf2, which is responsible for the induction of the transcription of major antioxidant enzymes, is required for the activation of cholesterol crystal-induced NLRP3 activation [37]. To better understand the relationship between NLRP3 and the Nrf2/HO-1 pathway, Nrf2-knockdown SW982 cells were treated with LPS. As shown in Fig. 9b, c, NLRP3 expression was significantly upregulated in the Nrf2knockdown group compared with the siRNA control group. In general, Nrf2 activation is considered to have anti-inflammatory effects via the regulation of genes encoding proinflammatory cytokines that are involved in inflammation [38]. Our study results suggest that the activation of the NLRP3 inflammasome is induced by ROS after stimulation with LPS, and changes in ROS levels provide a direct interpretation of the anti-inflammatory activity of the $\mathrm{Nrf} 2 / \mathrm{HO}-1$ signaling pathway.
Additionally, the upregulation of $\mathrm{HO}-1$ expression is important for cell protection under oxidative stress and inflammation conditions. A recent study reported that antioxidant proteins expression is increased after the activation of the Nrf2/HO-1 pathway, which in turn reduces inflammation and oxidative stress [39]. The heat shock protein family member $\mathrm{HO}-1$ is an important anti-inflammatory, antioxidative, and cytoprotective enzyme that is regulated by the activation of the major transcription factor Nrf2 [40, 41]. Wu et al. [42] showed that Nrf2 activation and HO-1 induction exert antiinflammatory effects and ROS inhibition. Consistent with this finding, as shown in Fig. 9a, there was no significant difference in the basal ROS levels between control siRNA- and siNrf2-treated cells, as assessed by using DHE staining; however, the LPS-induced level of ROS was enhanced in siNrf2-treated cells compared with control siRNA-treated cells.

Although we found that Nrf2, HO-1, NLRP3, and ASC were expressed in the knee synovia of patients with osteoarthritis, concrete evidence for the relationship between these genes and OA is still missing. In addition, due to the limitations of this study, the exact relationship between the synovium and the articular cartilage has not been clearly illustrated. Among inflammatory models, the ACLT+MMD rat model is of particular interest since it reproduces the main symptoms of OA at both the clinical and biological levels. However, this

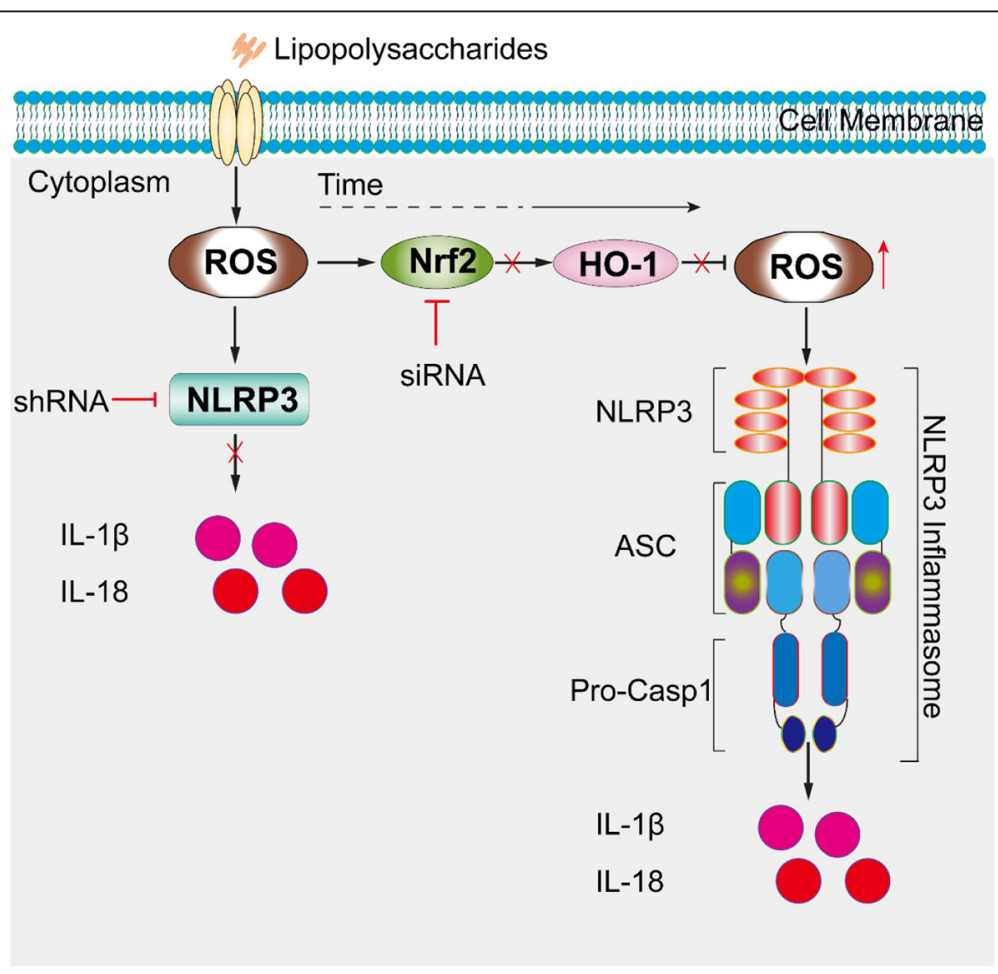

Fig. 10 The proposed pathway of NLRP3 inflammasome activation in SW982 cells stimulated with LPS 
model does not completely simulate the entire process of $\mathrm{OA}$ in humans because it is a degenerative disease rather than a trauma-induced disease in most circumstances. Moreover, the cellular response to the inhibition of the Nrf2/HO-1 pathway is still unclear, even though the results of our study suggest that the NLRP3 inflammasome is activated by the ROS pathway in vivo.

\section{Conclusions}

Taken together, the findings of our study demonstrate that oxidative stress leads to the activation of the NLRP3 inflammasome. Nrf2, HO-1, NLRP3, and ASC are highly expressed in the synovia of OA patients and OA model rats. Furthermore, we found reducing Nrf2 expression leads to the upregulation of NLRP3 expression in vitro, as illustrated in Fig. 10, which may be a pivotal process in the development of OA. Therefore, it is reasonable to speculate that targeting Nrf2 signaling might be a promising and attractive therapeutic strategy to prevent OA.

\section{Abbreviations}

ASC: Apoptosis-associated speck-like protein containing a CARD:

ATP: Adenosine triphosphate; BMD: Bone mineral density; BV: Bone volume; CT: Computed tomography; DHE: Dihydroethidium; DMEM: Dulbecco's modified Eagle's medium; EDTA: Ethylenediaminetetraacetic acid; ELISA: Enzyme-linked immunosorbent assay; FBS: Fetal bovine serum; GAPDH: Glyceraldehyde 3-phosphate dehydrogenase; H\&E: Hematoxylin and eosin; HBSS: Hank's balanced salt solution; HO-1: Heme oxygenase 1; IHC: Immunohistochemistry; IL: Interleukin; LPS: Lipopolysaccharide; NADPH: Nicotinamide adenine dinucleotide phosphate; NLRP3: Nucleotidebinding and oligomerization domain-like receptor containing protein 3 ; Nrf2: Nuclear factor-erythrocyte 2 related factor 2; OA: Osteoarthritis; OARSI: Osteoarthritis Research Society International; PVDF: Polyvinylidene fluoride; ROS: Reactive oxygen species; SD: Sprague-Dawley; SDS-PAGE: SDSpolyacrylamide gel electrophoresis; TBS-T: Tris-buffered saline-Tween 20; TV: Tissue volume

\section{Acknowledgements}

Not applicable.

\section{Authors' contributions}

JQC conceived the study and drafted the manuscript. ZMC, HZ, and JSW performed the experiments. SEL participated in critical review of the manuscript for intellectual content. ZXZ, FG, XQH, JHS, PL, HL, and BW collected the samples and contributed to the data acquisition and analysis. All authors read and approved the final manuscript.

\section{Funding}

This work was supported by National Natural Science Foundation of China (Grant No. 81771612) and the Stem Cell Preclinical Research Projects of the Affiliated Hospital of Guangdong Medical University (Grant No. 2018PSSC005)

\section{Availability of data and materials}

The datasets analyzed during the current study are available from the corresponding author on reasonable request.

\section{Ethics approval and consent to participate}

All human tissues were obtained and used with the informed consent of the patients and under the approval of the Committee of Medical Ethics at the Affiliated Hospital of Guangdong Medical University. The animal studies were approved by the Animal Care and Experiment Committee of Guangdong Medical University.
Consent for publication

Not applicable.

\section{Competing interests}

The authors declare that they have no competing interests.

\section{Author details}

'Orthopedic Center, Affiliated Hospital of Guangdong Medical University, Zhanjiang 524001, China. ²Department of Gastroenterology, Affiliated Hospital of Guangdong Medical University, Zhanjiang 524001, China. ${ }^{3}$ Stem Cell Research and Cellular Therapy Center, Affiliated Hospital of Guangdong Medical University, Zhanjiang 524001, China.

Received: 26 September 2019 Accepted: 6 December 2019

Published online: 23 December 2019

\section{References}

1. Egloff C, Hügle T, Valderrabano V. Biomechanics and pathomechanisms of osteoarthritis. Swiss Med Wkly. 2012;142(14):w13583.

2. Hermann W, Lambova S, Muller-Ladner U. Current treatment options for osteoarthritis. Curr Rheumatol Rev. 2018;14(2):108-16

3. Zhang W, Ouyang H, Dass CR, Xu J. Current research on pharmacologic and regenerative therapies for osteoarthritis. Bone Res. 2016;4:15040,

4. Rahmati M, Mobasheri A, Mozafari M. Inflammatory mediators in osteoarthritis: a critical review of the state-of-the-art, current prospects, and future challenges. Bone. 2016:85:81-90.

5. Cheleschi S, Tenti S, Mondanelli N, Corallo C, Barbarino M, Giannotti S, Gallo I, Giordano A, Fioravanti A. MicroRNA-34a and microRNA-181a mediate visfatin-induced apoptosis and oxidative stress via NF-kappaB pathway in human osteoarthritic chondrocytes. Cells. 2019;8(8):e874.

6. Franco-Trepat E, Guillan-Fresco M, Alonso-Perez A, Jorge-Mora A, Francisco V, Gualillo O, Gomez R. Visfatin connection: present and future in osteoarthritis and osteoporosis. J Clin Med. 2019:8(8):e1178.

7. Yan $\mathrm{M}$, Zhang J, Yang $\mathrm{H}$, Sun Y. The role of leptin in osteoarthritis. Medicine (Baltimore). 2018:97(14):e0257.

8. McAllister MJ, Chemaly M, Eakin AJ, Gibson DS, McGilligan VE. NLRP3 as a potentially novel biomarker for the management of osteoarthritis. Osteoarthr Cartil. 2018;26(5):612-9.

9. Jin C, Frayssinet P, Pelker R, Cwirka D, Hu B, Vignery A, Eisenbarth SC, Flavell RA. NLRP3 inflammasome plays a critical role in the pathogenesis of hydroxyapatite-associated arthropathy. Proc Natl Acad Sci U S A. 2011; 108(36):14867-72.

10. Place $D E$, Kanneganti TD. Recent advances in inflammasome biology. Curr Opin Immunol. 2018:50:32-8.

11. Kobayashi M, Squires GR, Mousa A, Tanzer M, Zukor DJ, Antoniou J, Feige U, Poole AR. Role of interleukin-1 and tumor necrosis factor alpha in matrix degradation of human osteoarthritic cartilage. Arthritis Rheum. 2005;52(1): $128-35$.

12. Olee T, Hashimoto S, Quach J, Lotz M. IL-18 is produced by articular chondrocytes and induces proinflammatory and catabolic responses. J Immunol. 1999;162(2):1096-100.

13. Guo H, Callaway JB, Ting JP. Inflammasomes: mechanism of action, role in disease, and therapeutics. Nat Med. 2015;21(7):677-87.

14. He Y, Hara H, Nunez G. Mechanism and regulation of NLRP3 inflammasome activation. Trends Biochem Sci. 2016:41(12):1012-21.

15. Hennig P, Garstkiewicz M, Grossi S, Di Filippo M, French LE, Beer HD. The Crosstalk between Nrf2 and inflammasomes. Int J Mol Sci. 2018;19(2):e562.

16. Altman R, Asch E, Bloch D, Bole G, Borenstein D, Brandt K, Christy W, Cooke TD, Greenwald R, Hochberg M, et al. Development of criteria for the classification and reporting of osteoarthritis. Classification of osteoarthritis of the knee. Diagnostic and Therapeutic Criteria Committee of the American Rheumatism Association. Arthritis Rheum. 1986;29(8):1039-49.

17. Lin S, Lee WYW, Feng $Q$, Xu L, Wang B, Man GCW, Chen Y, Jiang X, Bian L, Cui $L$, et al. Synergistic effects on mesenchymal stem cell-based cartilage regeneration by chondrogenic preconditioning and mechanical stimulation. Stem Cell Res Ther. 2017:8(1):221.

18. Scanzello CR, Goldring SR. The role of synovitis in osteoarthritis pathogenesis. Bone. 2012;51(2):249-57.

19. Zhou J, Zhao Y, Wu G, Lin B, Li Z, Liu X. Differential miRNAomics of the synovial membrane in knee osteoarthritis induced by bilateral anterior cruciate ligament transection in rats. Mol Med Rep. 2018;18(4):4051-7. 
20. Vaamonde-Garcia C, Loureiro J, Valcarcel-Ares MN, Riveiro-Naveira RR, RamilGomez O, Hermida-Carballo L, Centeno A, Meijide-Failde R, Blanco FJ, Lopez-Armada MJ. The mitochondrial inhibitor oligomycin induces an inflammatory response in the rat knee joint. BMC Musculoskelet Disord. 2017;18(1):254

21. Cai D, Yin S, Yang J, Jiang Q, Cao W. Histone deacetylase inhibition activates Nrf2 and protects against osteoarthritis. Arthritis Res Ther. 2015;17:269.

22. Martinon F, Tschopp J. Inflammatory caspases and inflammasomes: master switches of inflammation. Cell Death Differ. 2007;14(1):10-22.

23. Zheng SC, Zhu XX, Xue Y, Zhang LH, Zou HJ, Qiu JH, Liu Q. Role of the NLRP3 inflammasome in the transient release of IL-1beta induced by monosodium urate crystals in human fibroblast-like synoviocytes. J Inflamm (Lond). 2015;12:30

24. Santangelo KS, Nuovo GJ, Bertone AL. In vivo reduction or blockade of interleukin-1beta in primary osteoarthritis influences expression of mediators implicated in pathogenesis. Osteoarthr Cartil. 2012;20(12):1610-8.

25. Glasson SS. In vivo osteoarthritis target validation utilizing geneticallymodified mice. Curr Drug Targets. 2007;8(2):367-76.

26. Bougault C, Gosset M, Houard X, Salvat C, Godmann L, Pap T, Jacques C, Berenbaum F. Stress-induced cartilage degradation does not depend on the NLRP3 inflammasome in human osteoarthritis and mouse models. Arthritis Rheum. 2012;64(12):3972-81.

27. Fioravanti A, Tenti S, McAllister M, Chemaly M, Eakin A, McLaughlin J, Bjourson AJ, Frati E, McGilligan V, Cheleschi S, et al. Exploring the involvement of NLRP3 and IL-1beta in osteoarthritis of the hand: results from a pilot study. Mediat Inflamm. 2019;2019:2363460.

28. Clavijo-Cornejo D, Martinez-Flores K, Silva-Luna K, Martinez-Nava GA, Fernandez-Torres J, Zamudio-Cuevas Y, Guadalupe Santamaria-Olmedo M, Granados-Montiel J, Pineda C, Lopez-Reyes A. The overexpression of NALP3 inflammasome in knee osteoarthritis is associated with synovial membrane prolidase and NADPH oxidase 2. Oxidative Med Cell Longev. 2016;2016: 1472567.

29. Sun Y, Liu W, Zhang H, Li H, Liu J, Zhang F, Jiang T, Jiang S. Curcumin prevents osteoarthritis by inhibiting the activation of inflammasome NLRP3. J Interf Cytokine Res. 2017;37(10):449-55.

30. Zu Y, Mu Y, Li Q, Zhang ST, Yan HJ. Icariin alleviates osteoarthritis by inhibiting NLRP3-mediated pyroptosis. J Orthop Surg Res. 2019;14(1):307.

31. Nasi S, Ea HK, So A, Busso N. Revisiting the role of interleukin-1 pathway in osteoarthritis: interleukin-1alpha and -1beta, and NLRP3 inflammasome are not involved in the pathological features of the murine menisectomy model of osteoarthritis. Front Pharmacol. 2017;8:282.

32. Li D, Xie G, Wang W. Reactive oxygen species: the 2-edged sword of osteoarthritis. Am J Med Sci. 2012;344(6):486-90.

33. Kauppinen A, Niskanen H, Suuronen T, Kinnunen K, Salminen A, Kaarniranta K. Oxidative stress activates NLRP3 inflammasomes in ARPE-19 cells-implications for age-related macular degeneration (AMD). Immunol Lett. 2012;147(1-2):29-33.

34. Ziskoven C, Jager M, Kircher J, Patzer T, Bloch W, Brixius K, Krauspe R. Physiology and pathophysiology of nitrosative and oxidative stress in osteoarthritic joint destruction. Can J Physiol Pharmacol. 2011;89(7):455-66.

35. Poulet B, Beier F. Targeting oxidative stress to reduce osteoarthritis. Arthritis Res Ther. 2016;18:32

36. Zhang $X$, Zhang JH, Chen XY, Hu QH, Wang MX, Jin R, Zhang QY, Wang W, Wang $R$, Kang $L L$, et al. Reactive oxygen species-induced TXNIP drives fructose-mediated hepatic inflammation and lipid accumulation through NLRP3 inflammasome activation. Antioxid Redox Signal. 2015;22(10):848-70.

37. Freigang S, Ampenberger F, Spohn G, Heer S, Shamshiev AT, Kisielow J, Hersberger M, Yamamoto M, Bachmann MF, Kopf M. Nrf2 is essential for cholesterol crystal-induced inflammasome activation and exacerbation of atherosclerosis. Eur J Immunol. 2011:41(7):2040-51.

38. Suzuki T, Yamamoto M. Stress-sensing mechanisms and the physiological roles of the Keap1-Nrf2 system during cellular stress. J Biol Chem. 2017; 292(41):16817-24.

39. Luo JF, Shen XY, Lio CK, Dai Y, Cheng CS, Liu JX, Yao YD, Yu Y, Xie Y, Luo P, et al. Activation of Nrf2/HO-1 pathway by nardochinoid $C$ inhibits inflammation and oxidative stress in lipopolysaccharide-stimulated macrophages. Front Pharmacol. 2018;9:911.

40. Joo Choi R, Cheng MS, Shik KY. Desoxyrhapontigenin up-regulates Nrf2mediated heme oxygenase-1 expression in macrophages and inflammatory lung injury. Redox Biol. 2014;2:504-12.
41. Rosillo MA, Sanchez-Hidalgo M, Gonzalez-Benjumea A, Fernandez-Bolanos JG, Lubberts E, Alarcon-de-la-Lastra C. Preventive effects of dietary hydroxytyrosol acetate, an extra virgin olive oil polyphenol in murine collagen-induced arthritis. Mol Nutr Food Res. 2015;59(12):2537-46.

42. Wu WJ, Jia WW, Liu XH, Pan LL, Zhang QY, Yang D, Shen XY, Liu L, Zhu YZ. S-propargyl-cysteine attenuates inflammatory response in rheumatoid arthritis by modulating the Nrf2-ARE signaling pathway. Redox Biol. 2016;10: 157-67.

\section{Publisher's Note}

Springer Nature remains neutral with regard to jurisdictional claims in published maps and institutional affiliations.
Ready to submit your research? Choose BMC and benefit from:

- fast, convenient online submission

- thorough peer review by experienced researchers in your field

- rapid publication on acceptance

- support for research data, including large and complex data types

- gold Open Access which fosters wider collaboration and increased citations

- maximum visibility for your research: over $100 \mathrm{M}$ website views per year

At BMC, research is always in progress.

Learn more biomedcentral.com/submissions 